\title{
PREDICTION OF CORONARY ARTERY DISEASE BY DETECTION OF POSITIVE ISOVOLUMIC RELAXATION VELOCITY IN PATIENTS WITH NORMAL RESTING WALL MOTIONS \\ "A Tissue Doppler Echocardiographic Study"
}

\author{
Abdelfattah Hassan Frer, Magdy Mohamed Abdelsamie, Maha Hamed Elsebaie \\ and Ahmed Said Eldamanhory* \\ Cardiology Department, Faculty of Medicine, Zagazig University.
}

\begin{abstract}
Background: Diagnosis of coronary artery disease (CAD) is of importance in the contemporary society of everincreasing CAD ${ }^{(\mathbf{1}, 2)}$. Isovolumic relaxation velocity (VIR), Postsystolic motion or postsystolic shortening (PSS) is a delayed ejection motion of the myocardium occurring after the aortic valve closure during a generally prolonged isovolumic relaxation time, which is related with myocardial ischemia in human $^{(\mathbf{3}, \mathbf{4})}$ and in experimental studies ${ }^{(\mathbf{5})}$. Spectral tissue Doppler imaging (TDI) is a simple echocardiographic technique that can provide velocity measurement of the myocardial segments ${ }^{(\mathbf{6})}$. A positive myocardial velocity during isovolumic relaxation phase (VIR) detected by TDI, which corresponds to postsystolic motion or PSS, has been shown to indicate severely ischemic myocardium ${ }^{(\mathbf{8})}$. So, detection of positive VIR by spectral TDI may be used as a noninvasive, nonprovocative method to predict possible CAD; specially for those with coexisting morbidities, such as peripheral artery disease in the lower limb, orthopedic diseases. Aim of the work: Diagnostic value of positive myocardial velocity during isovolumic relaxation phase (VIR) by spectral TDI in prediction of CAD in patients with typical ischemic chest pain and normal resting wall motions. Patients and methods: This study was done in Cardiology department, Zagazig University on 80 patients; 41 females $(51 \%)$ \& 39 males $(49 \%)$ ) with typical ischemic chest pain and no regional wall motion abnormalities detected by resting echocardiography. Patients were divided into 2 groups according to presence of significant coronary artery lesion by coronary angiography; group A (patients with CAD) and group B (patients without CAD). All the following parameters were measured by TDI; 5 peak velocities during; Isovolumic contraction phase (VIC), Systolic ejection phase ( $\left.\mathrm{S}^{\prime}\right)$, Early diastolic relaxation phase (Em), Atrial contraction phase (Am) and Isovolumic relaxation phase (VIR) if present and VIR time. Then coronary angiography was done for all patients. Results: As regard to presence of VIR velocity, there was significant difference $(<0.05)$ between group A and group B at mid septal and anterior walls, highly significant difference $(<0.001)$ at basal septal and anterior walls. There was highly significant difference between group $\mathrm{A}$ and $\mathrm{B}$ at mid and basal lateral and inferior walls. There was highly significant correlation between coronary angiography and VIR velocity regarding detection of positive and negative cases and also there was highly significant correlation between previous 2 tests by Kappa test $\mathrm{p}$ value $(<0.001)$. Conclusion: Positive VIR detected by spectral tissue Doppler imaging is a useful indicator of CAD in patients with apparently normal left ventricular contraction and chest pain.
\end{abstract}

Key words: TDI, VIR velocity, coronary angiofraphy, coronary artery disease.

\section{INTRODUCTION}

D iagnosis of coronary artery disease (CAD) is of importance in the cont-emporary society of ever-increasing $\mathrm{CAD}^{(1,2)}$. Exercise electrocardiography has found wide acceptance for CAD identification because of low cost. However, a substantial number of patients are unable to do exercise. It would be desirable if the detection of CAD could be done without any provocation. Postsystolic motion or postsystolic shortening (PSS) is a delayed ejection motion of the myocardium occurring after the aortic valve closure during a generally prolonged isovolumic relaxation time, which is related with myocardial ischemia in patients ${ }^{(3,4)}$. and in experimental studies $^{(5)}$.

PSS detected by strain rate imaging during dobutamine stress echocar-diography has been suggested as an indicator of $\mathrm{CAD}^{(7)}$.

On the other hand, spectral tissue Doppler imaging (TDI) is a simple echocardiographic technique that provides velocity measurements of the myocardial wall ${ }^{(6)}$ and runs in standard cardiac ultrasound diagnostic equipment.

A positive myocardial velocity during isovolumic relaxation phase (VIR) detected by TDI, which corresponds to postsystolic motion or PSS, has been shown to indicate severely ischemic myocardium ${ }^{(8)}$.

Detection of positive VIR by spectral TDI may be used as a noninvasive, nonprovocative method to predict possible CAD specially for those with coexisting morbidities, such as peripheral artery disease in the lower limb, orthopedic diseases, and old cerebral infarction in whom standard 2 dimensional echocard-iography does not reveal LV asynergy.

\section{AIM OF THE WORK}

The purpose of this study is to examine the diagnostic value of positive myocardial velocity during isovolumic relaxation phase (VIR) by spectral TDI in prediction of CAD in patients with typical ischemic chest pain and normal resting wall motions. 


\section{PATIENTS AND METHODS}

We enrolled 80 patients with chest pain and normal LV wall motion detected by standard echocardiography who agreed to the study protocol in the period between April 2011 and December 2012, We grouped them according to result of coronary angiography into:

- Group A: patients with coronary artery disease.

- Group B: patients without coronary artery disease.

Exclusion criteria: Patients with history of overt heart diseases such as myocardial infarction, coronary angio-plasty or bypass grafting, atrial fibrillation or flutter, pacemaker implantation, left bundle branch block (LBBB), significant valvular diseases, dilated or restrictive cardiomyopathies, LV hypertrophy (interventricular septum or posterior wall thickness-12mm), pulmonary hypertension (tricuspid valve regurgitation velocity- $2.5 \mathrm{~m} / \mathrm{s}$ ), congestive heart failure and patient with inadequate ultrasound images were excluded.

Our patients will be subjected to the following; complete history taking, thorough clinical examination, 12 lead surface electrocardiogram (ECG), full laboratory analysis, including (Tnt, lipid profile, RBs, liver and Kidney functions).

Patients underwent spectral TDI addition to standard echocardiography. Subsequently, patients underwent coronary angiography. The study protocol was approved by our ethics committee. All patients gave written informed consent.

\section{Echocardiography}

All patients underwent routine echocardiography and spectral TDI using commercially available cardiac ultrasound diagnostic equipment (HP- 5500, Sonos Ultrasound) with a $4 \mathrm{MHz}$ transducer with adequate settings for spectral TDI recommended by the manufacturers. Echo-cardiograms were obtained in the left lateral position at end expiration. No stress was placed on the patients. LV end-diastolic and end-systolic dimensions were measured in 2-dimensional guided M-mode echocardiograms ${ }^{(9)}$. Spectral Tissue Doppler Velocity Mapping Spectral TDI measurements were done at the annular and mid-LV levels (4 points) in the apical 4 - and 2-chamber views ( 8 points in each patient). A fixed sampling gate of 8 $\mathrm{mm}$ was placed equidistant between the endocardial and epicardial borders. Care was taken to align the echocardiographic image so that the LV wall was parallel to the TDI cursor. Spectral Doppler signal parameters were adjusted to obtain Nyquist limits between 15 and $20 \mathrm{~cm} / \mathrm{s}$ using the lowest filter settings. Gain was adjusted to minimize noise and to eliminate the signals produced by the blood flow. From spectral TDI tracings, we obtained 5 peak velocities (Figure1): during isovolumic contraction phase; during systolic ejection phase; VIR; during early diastolic relaxation phase; and during atrial contraction phase. VIR was found between the end of systolic ejection phase and the onset of early diastolic relaxation phase. Positive VIR was defined as an upward spike found between the end of systolic ejection phase and the onset of early diastolic relaxation phase. The presence of positive VIR in more than one of the 8 points in each patient was judged as positive for CAD. The duration of positive VIR was also assessed.

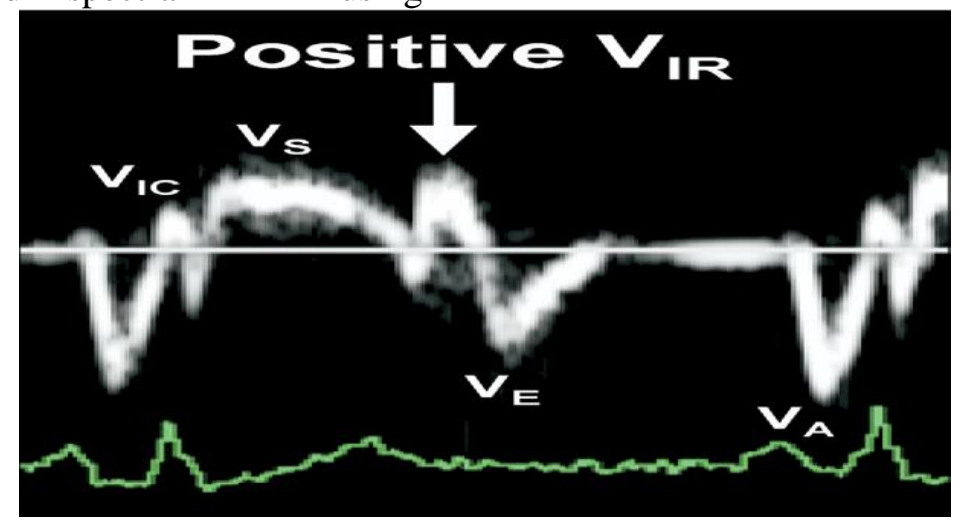

Figure (1): Myocardial velocity (V) by spectral tissue Doppler imaging. Prominent positive myocardial V during isovolumic relaxation phase(VIR). VA, Atrial contraction; VE, early diastolic filling; VIC, isovolumic contraction; VS, systolic ejection.

\section{Coronary angiography:}

Eighty patients underwent coronary angiography with multiple views. coronary angiography was interpreted by consensus opinion of two physicians who were unaware of the results of TDI findings. Coronary narrowing in one or more major vessels was graded by visual analysis according to the lumen diameter involved: $25 \%$ or 
less; $26 \%$ to $50 \%$; $51 \%$ to $75 \%$; $76 \%$ to $90 \%$; $91 \%$ to $99 \%$; or $100 \%$. Critical coronary artery stenosis was defined as having more than $75 \%$ diameter stenosis. CAD was diagnosed when patients had a critical coronary artery stenosis by CAG. Thus, the diagnosis of $\mathrm{CAD}$ was finally confirmed by CAG in all patients.

\section{Reproducibility of Measurements:}

Ten patients were randomly selected to determine reproducibility of the measurements of the duration of positive VIR. Spectral TDI tracings were analyzed by a single observer on two occasions (intraobserver variability) and by two independent observers (interobserber variability). Mean values of the absolute difference in the measurements were $12 \pm 24$ milliseconds (intraobserver variability) and $14 \pm 33$ milliseconds (intrerobserver variability) for the duration of positive VIR.

\section{Statistical Analysis:}

According to the type of data, the following tests were used to test differences for significance; Differences between frequencies (qualitative

Demographic data of the study population:

The study included 41 females (51\%) and 39 males (49\%).with highly significant difference variables) in groups were compared by Chi-square test. Differences between means (quantitative variables) in two groups were compared by Student's t-test, paired two group by paired t test. Correlation between quantitative data calculated by persons' correlation and between qualitative and quantitative by general linear model (GLM). $P$ value was set at $<0.05$ for significant results. Optimal cut-off values of VIR velocity and the duration of the positive VIR for discriminating normal from patients with CAD was obtained from receiver operating characteristic curves

\section{RESULTS}

The study included 80 patients presented with ischemic chest pain. They were classified into two groups: Group I (coronary artery disease); it included 60 patients; 33 male and 27 females. Age ranged from 56 to 68 years with mean \pm SD of $62 \pm 5.5$. Group II (normal coronary angiography); it included 20 subjects; 6 male and 14 females. Age ranged from 47 to 64 years with mean \pm SD of $55.6 \pm 8.6$.

between the two groups as regard age, HTN, smoking and dyslipidemia.

Table (1) Tissue Doppler finding LV septal wall of study groups:

\begin{tabular}{|c|c|c|c|}
\hline MID LEVEL & Group(A) & Group(B) & $\mathrm{P}$ \\
\hline S'wave velocity $(\mathrm{cm} / \mathrm{sec})$ & $8 \pm 2.4$ & $13.2 \pm 2.3$ & $<0.001$ \\
\hline Em wave velocity $(\mathrm{cm} / \mathrm{sec})$ & $9.7 \pm 2.4$ & $10.6 \pm 3.1$ & $\mathrm{NS}$ \\
\hline Am wave velocity $(\mathrm{cm} / \mathrm{sec})$ & $12.7 \pm 4.3$ & $13.7 \pm 3$ & $\mathrm{NS}$ \\
\hline VIC velocity $(\mathrm{cm} / \mathrm{sec})$ & $10 \pm 3$ & $9.1 \pm 2$ & $\overline{\mathrm{NS}}$ \\
\hline VIR velocity $(\mathrm{cm} / \mathrm{sec})$ & $4.3 \pm 3.4$ & $4 \pm 1.6$ & $<0.05$ \\
\hline VIR Time(msec) & $82.5 \pm 67$ & $16 \pm 39$ & $<0.001$ \\
\hline \multicolumn{4}{|l|}{ BASALLEVEL } \\
\hline $\mathrm{S}^{\prime}$ velocity $(\mathrm{cm} / \mathrm{sec})$ & $10.5 \pm 2.9$ & $11.7 \pm 2.1$ & $\mathrm{NS}$ \\
\hline Emwave velocity $(\mathrm{cm} / \mathrm{sec})$ & $11 \pm 2.5$ & $13.6 \pm 2.4$ & $<0.001$ \\
\hline Amwave velocity $(\mathrm{cm} / \mathrm{sec})$ & $16.1 \pm 4.6$ & $9.6 \pm 2.5$ & $<0.001$ \\
\hline VIC velocity $(\mathrm{cm} / \mathrm{sec})$ & $11.4 \pm 4$ & $8.5 \pm 2$ & $<0.05$ \\
\hline VIR velocity $(\mathrm{cm} / \mathrm{sec})$ & $7.2 \pm 4.2$ & $2.4 \pm 0.95$ & $<0.001$ \\
\hline VIR Time(msec) & $107.7 \pm 54$ & $16.5 \pm 40$ & $<0.001$ \\
\hline $\begin{array}{l}\text { At mid septal wall; } \mathrm{S}^{\prime} \text { wave was } 8 \pm 2.4 \mathrm{~cm} / \mathrm{sec} \\
\text { in group A and } 13.2 \pm 2.3 \mathrm{~cm} / \mathrm{sec} \text { in group B with } \\
\text { highly significant decrease in group A, VIR } \\
\text { velocity was } 4.3 \pm 3.4 \mathrm{~cm} / \mathrm{sec} \text { in group A and } 4 \pm 1.6 \\
\mathrm{~cm} / \mathrm{sec} \text { in group B with significant increase in } \\
\text { group A, VIR time was } 82.5 \pm 67 \mathrm{msec} \text { in group A } \\
\text { and } 16 \pm 39 \mathrm{msec} \text { in group B with highly significant } \\
\text { increase in group A. At basal septal wall; Em } \\
\text { wave } 11 \pm 2.5 \mathrm{~cm} / \mathrm{sec} \text { and } 13.6 \pm 2.4 \mathrm{~cm} / \mathrm{sec} \text { with } \\
\text { highly significant decrease in group A, Am wave }\end{array}$ & \multicolumn{3}{|c|}{$\begin{array}{l}\text { was } 16.1 \pm 4.6 \mathrm{~cm} / \mathrm{sec} \text { in group A and } 9.6 \pm 2.5 \\
\mathrm{~cm} / \mathrm{sec} \text { in group B with highly significant } \\
\text { difference in group A, VIC velocity was } 11.4 \pm 4 \\
\mathrm{~cm} / \mathrm{sec} \text { in group A and } 8.5 \pm 2 \text { in group B with } \\
\text { significant increase in group A, VIR velocity was } \\
7.2 \pm 4.2 \mathrm{~cm} / \mathrm{sec} \text { in group A and } 2.4 \pm 0.95 \mathrm{~cm} / \mathrm{sec} \text { in } \\
\text { group B with highly significant increase in group } \\
\text { A, VIR time was } 107.7 \pm 54 \text { msec in group A and } \\
16.5 \pm 40 \text { in group B with highly significant } \\
\text { increase in group A. }\end{array}$} \\
\hline
\end{tabular}


Table (2) Tissue Doppler finding LV lateral wall of study group:

\begin{tabular}{lrrr}
\hline MID LEVEL & Group(A) & Group(B) & P \\
\hline S' velocity $(\mathrm{cm} / \mathrm{sec})$ & $7.9 \pm 3$ & $12.9 \pm 2.9$ & $<0.001$ \\
\hline Em wave velocity $(\mathrm{cm} / \mathrm{sec})$ & $10.6 \pm 3.4$ & $11 \pm 2.6$ & $<0.05$ \\
\hline Am wave velocity $(\mathrm{cm} / \mathrm{sec})$ & $10.3 \pm 3.3$ & $9 \pm 3.2$ & $\mathrm{NS}$ \\
\hline VIC velocity $(\mathrm{cm} / \mathrm{sec})$ & $10.2 \pm 3$ & $\wedge . \wedge \pm \mathbf{r} .4$ & $<0.05$ \\
\hline VIR velocity $(\mathrm{cm} / \mathrm{sec})$ & $4.6 \pm 3.7$ & $2.6 \pm 0.85$ & $<0.001$ \\
\hline VIR Time $(\mathrm{msec})$ & $84.5 \pm 64$ & $34 \pm 11$ & $<0.001$ \\
\hline BASAL LEVEL & & & \\
\hline S' velocity $(\mathrm{cm} / \mathrm{sec})$ & $11.3 \pm 4.4$ & $13.1 \pm 2.9$ & $\mathrm{NS}$ \\
\hline Emwave velocity $(\mathrm{cm} / \mathrm{sec})$ & $12.4 \pm 4.1$ & $13.6 \pm 2.9$ & $\mathrm{NS}$ \\
\hline Amwave velocity(cm/sec) & $16.1 \pm 4.6$ & $10.3 \pm 2.6$ & $<0.001$ \\
\hline VIC velocity $(\mathrm{cm} / \mathrm{sec})$ & $11.6 \pm 3.9$ & $10.5 \pm 3.3$ & $\mathrm{NS}$ \\
\hline VIR velocity $(\mathrm{cm} / \mathrm{sec})$ & $6.9 \pm 4.9$ & $3.2 \pm 1.5$ & $<0.001$ \\
\hline VIR Time $(\mathrm{msec})$ & $96.5 \pm 50.2$ & $21 \pm 43$ & $<0.001$ \\
\hline
\end{tabular}

At mid lateral wall; $S^{\prime}$ wave velocity was $7.9 \pm 3 \mathrm{~cm} / \mathrm{sec}$ in group A and $12.9 \pm 2.9 \mathrm{~cm} / \mathrm{sec}$ in group B with highly significant increase in group A, Em wave velocity was $10.6 \pm 3.4 \mathrm{~cm} / \mathrm{sec}$ in group A and $11 \pm 2.6 \mathrm{~cm} / \mathrm{sec}$ in group B with significant decrease in group A, VIC velocity was $10.2 \pm 3 \mathrm{~cm} / \mathrm{sec}$ in group A and $8.8 \pm 2.4$ in group b with significant increase in group A, VIR wave velocity was $4.6 \pm 3.7 \mathrm{~cm} / \mathrm{sec}$ in group $A$ and $2.6 \pm 0.85 \mathrm{~cm} / \mathrm{sec}$ in group $\mathrm{B}$ with highly significant difference increase in group A, VIR time was $84.5 \pm 64 \mathrm{msec}$ in group $A$ and $34 \pm 11$ in group B with highly significant increase in group A .

At basal lateral wall; Am wave velocity was $16.1 \pm 4.6 \mathrm{~cm} / \mathrm{sec}$ in group A and $10.3 \pm 2.6 \mathrm{~cm} / \mathrm{sec}$ in group B with highly significant increase in group A, VIR wave velocity was $6.9 \pm 4.9 \mathrm{~cm} / \mathrm{sec}$ in group A and $3.2 \pm 1.5 \mathrm{~cm} / \mathrm{sec}$ in group B with highly significant increase in group A, VIR time was $96.5 \pm 50.2 \mathrm{msec}$ in group a and $21 \pm 43 \mathrm{msec}$ in group B with highly significant increase in group A.

Table (3) T issue Doppler finding LV anterior wall of study group:

\begin{tabular}{lccc}
\hline MID LEVEL & Group $(\mathrm{A})$ & Group(B) & P \\
\hline S' velocity(cm/sec) & $6.9 \pm 1.9$ & $12.2 \pm 2.5$ & $<0.001$ \\
\hline Em wave velocity(cm/sec) & $8.7 \pm 2.4$ & $10.8 \pm 2.9$ & $<0.05$ \\
\hline Amwave velocity(cm/sec) & $10.2 \pm 3.8$ & $12.2 \pm 4.4$ & $\mathrm{NS}$ \\
\hline VIC velocity(cm/sec) & $9.1 \pm 3.2$ & $9.5 \pm 2.4$ & $\mathrm{NS}$ \\
\hline VIR velocity(cm/sec) & $4.1 \pm 3.5$ & $1.1 \pm 2.8$ & $<0.05$ \\
\hline VIR Time(msec) & $82.4 \pm 66.6$ & $17.3 \pm 4.1$ & $<0.001$ \\
\hline BASAL LEVEL & & & $\mathrm{NS}$ \\
\hline S' velocity $(\mathrm{cm} / \mathrm{sec})$ & $9.5 \pm 3.5$ & $9.8 \pm 2.9$ & $\mathrm{NS}$ \\
\hline Emwave velocity(cm/sec) & $12.2 \pm 3.1$ & $13.4 \pm 3.1$ & $<0.001$ \\
\hline Amwave velocity(cm/sec) & $16.2 \pm 5.3$ & $9.9 \pm 3.4$ & $<0.001$ \\
\hline VIC velocity $(\mathrm{cm} / \mathrm{sec})$ & $11.7 \pm 3.3$ & $8.7 \pm 2$ & $<0.001$ \\
\hline VIR velocity $(\mathrm{cm} / \mathrm{sec})$ & $6.3 \pm 5.5$ & $1.2 \pm 2.7$ & $<0.001$ \\
\hline VIR Time(msec) & $102.5 \pm 43.3$ & $20.6 \pm 42.4$ & \\
\hline
\end{tabular}

At mid anterior wall; $\mathrm{S}^{\prime}$ wave velocity was $6.9 \pm 1.9 \mathrm{~cm} / \mathrm{sec}$ in group A and $12.2 \pm 2.5 \mathrm{~cm} / \mathrm{sec}$ in group B with highly significant decrease in group A, Em wave velocity was $8.7 \pm 2.4 \mathrm{~cm} / \mathrm{sec}$ in group $\mathrm{A}$ and $10.8 \pm 2.9 \mathrm{~cm} / \mathrm{sec}$ in group B with significant decrease in group A, VIR wave velocity was $4.1 \pm 3.5 \mathrm{~cm} / \mathrm{sec}$ in group A and $1.1 \pm 2.8 \mathrm{~cm} / \mathrm{sec}$ in group B, VIR time was $82.4 \pm 66.6 \mathrm{msec}$ in group $\mathrm{A}$ and $17.3 \pm 4.1 \mathrm{msec}$ in group $\mathrm{B}$ with highly significant increase in group A.
At basal anterior wall; Am wave velocity was $16.2 \pm 5.3 \mathrm{~cm} / \mathrm{sec}$ in group A and $9.9 \pm 3.4$ in group B with highly significant increase in group A, VIC wave velocity was $11.7 \pm 3.3 \mathrm{~cm} / \mathrm{sec}$ in group A and $8.7 \pm 2 \mathrm{~cm} / \mathrm{sec}$ in group B with highly significant increase in group A, VIR wave velocity was $6.3 \pm 5.5 \mathrm{~cm} / \mathrm{sec}$ in group $\mathrm{A}$ and $\mathrm{V}$ $\mathrm{cm} / \mathrm{sec}$ in group B with highly significant increase in group A, VIR time was $102.5 \pm 43.3 \mathrm{msec}$ in group A and $20.6 \pm 42.4 \mathrm{msec}$ in group B with highly significant increase in group A. 
Table (4) T issue Doppler finding LV inferior wall of study group:

\begin{tabular}{lccc}
\hline MID LEVEL & Group(A) & Group(B) & P \\
\hline S' velocity $(\mathrm{cm} / \mathrm{sec})$ & $9 \pm 3.4$ & $9.9 \pm 2.7$ & $\mathrm{NS}$ \\
\hline Em wave velocity(cm/sec) & $9 \pm 2.2$ & $9.5 \pm 3$ & $\mathrm{NS}$ \\
\hline Amwave velocity(cm/sec) & $11.9 \pm 3.4$ & $13.1 \pm 2.9$ & $\mathrm{NS}$ \\
\hline VIC velocity $(\mathrm{cm} / \mathrm{sec})$ & $9 \pm 3$ & $6.8 \pm 2.2$ & $<0.05$ \\
\hline VIR velocity $(\mathrm{cm} / \mathrm{sec})$ & $5.3 \pm 3.5$ & $1 \pm 4.9$ & $<0.001$ \\
\hline VIR Time $(\mathrm{msec})$ & $102.8 \pm 69.5$ & $16 \pm 39.2$ & $<0.001$ \\
\hline BASAL LEVEL & & & \\
\hline S' velocity $(\mathrm{cm} / \mathrm{sec})$ & $9.6 \pm 3.5$ & $9.8 \pm 2.9$ & $\mathrm{NS}$ \\
\hline Emwave velocity $(\mathrm{cm} / \mathrm{sec})$ & $11.2 \pm 2.3$ & $12.7 \pm 2.4$ & $<0.05$ \\
\hline Amwave velocity $(\mathrm{cm} / \mathrm{sec})$ & $15.7 \pm 4.3$ & $10.5 \pm 3$ & $<0.001$ \\
\hline VIC velocity $(\mathrm{cm} / \mathrm{sec})$ & $11.7 \pm 3.4$ & $8.8 \pm 2$ & $<0.001$ \\
\hline VIR velocity $(\mathrm{cm} / \mathrm{sec})$ & $6.3 \pm 5.6$ & $1.3 \pm 2.8$ & $<0.001$ \\
\hline VIR Time $(\mathrm{msec})$ & $82.9 \pm 55.9$ & $21.8 \pm 44.9$ & $<0.001$ \\
\hline
\end{tabular}

At mid inferior wall; VIC wave velocity was $9 \pm 3 \mathrm{~cm} / \mathrm{sec}$ in group $\mathrm{A}$ and $6.8 \pm 2.2 \mathrm{~cm} / \mathrm{sec}$ in group B with significant increase in group A, VIR wave velocity was $5.3 \pm 3.5 \mathrm{~cm} / \mathrm{sec}$ in group A and $1 \pm 4.9 \mathrm{~cm} / \mathrm{sec}$ in group B with significant increase in group A, VIR time was $82.9 \pm 55.9 \mathrm{msec}$ in group A and $16 \pm 39.2 \mathrm{msec}$. in group B with highly significant increase in group A.

At basal inferior wall; Em wave velocity was $11.2 \pm 2.3 \mathrm{~cm} / \mathrm{sec}$ in group A and $12.7 \pm 2.4 \mathrm{~cm} / \mathrm{sec}$ in group B with significant decrease in group A,
Am wave velocity was $15.7 \pm 4.3 \mathrm{~cm} / \mathrm{sec}$ in group A and $10.5 \pm 3 \mathrm{~cm} / \mathrm{sec}$ in group B with highly significant increase in group A, VIC wave velocity was $11.7 \pm 3.4 \mathrm{~cm} / \mathrm{sec}$ in group $A$ and $8.8 \pm 2 \mathrm{~cm} / \mathrm{sec}$ in group B with highly significant increase in group A, VIR wave velocity was $6.3 \pm 5.6 \mathrm{~cm} / \mathrm{sec}$ in group A and $1.3 \pm 2.8 \mathrm{~cm} / \mathrm{sec}$ in group B with highly significant increase in group $\mathrm{A}$, VIR time was $82.9 \pm 55.9 \mathrm{msec}$ in group A and $21.8 \pm 44.9 \mathrm{msec}$ in group B with highly significant increase in group A.

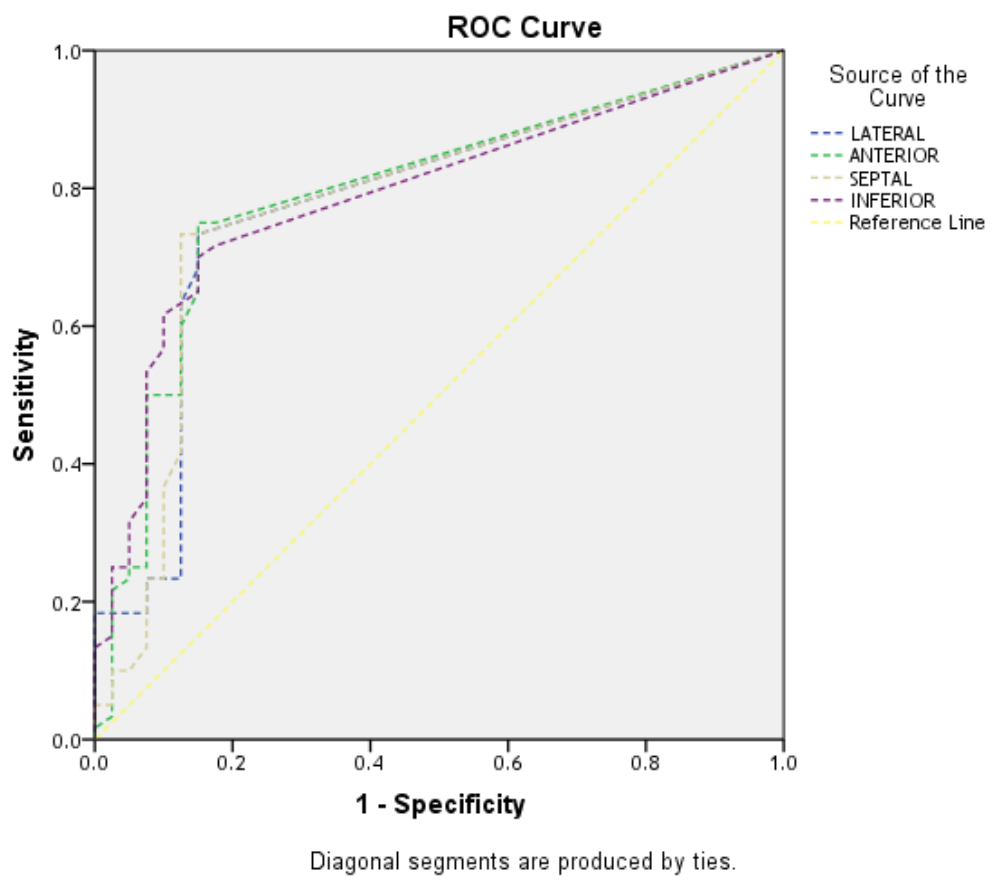


VIR velocity detected in lateral wall with cut off value $4.8 \mathrm{~cm} / \mathrm{sec}$. has $69.5 \%$ sensitivity, $85 \%$ specificity with $92.2 \%$ +ve predictive, $51.2 \%$-ve predictive and accuracy $72.2 \%$

VIR velocity detected in anterior wall with cut off value $4.1 \mathrm{~cm} / \mathrm{sec}$. has $63.3 \%$ sensitivity $80 \%$ specificity with $90.4 \%+v e$ predictive, $42.1 \%$-ve predictive and accuracy $67.5 \%$.
VIR velocity detected in septal wall with cut off value $4.4 \mathrm{~cm} / \mathrm{sec}$. has $63.3 \%$ sensitivity $85 \%$ specificity with $92.8 \%$ +ve predictive, $44.7 \%$-ve predictive and accuracy $70 \%$.

VIR velocity detected in inferior wall with cut off value $4.2 \mathrm{~cm} / \mathrm{sec}$. has $73.3 \%$ sensitivity, $80 \%$ specificity with $91.6 \%$ +ve predictive, $50 \%$-ve predictive and accuracy $70 \%$.

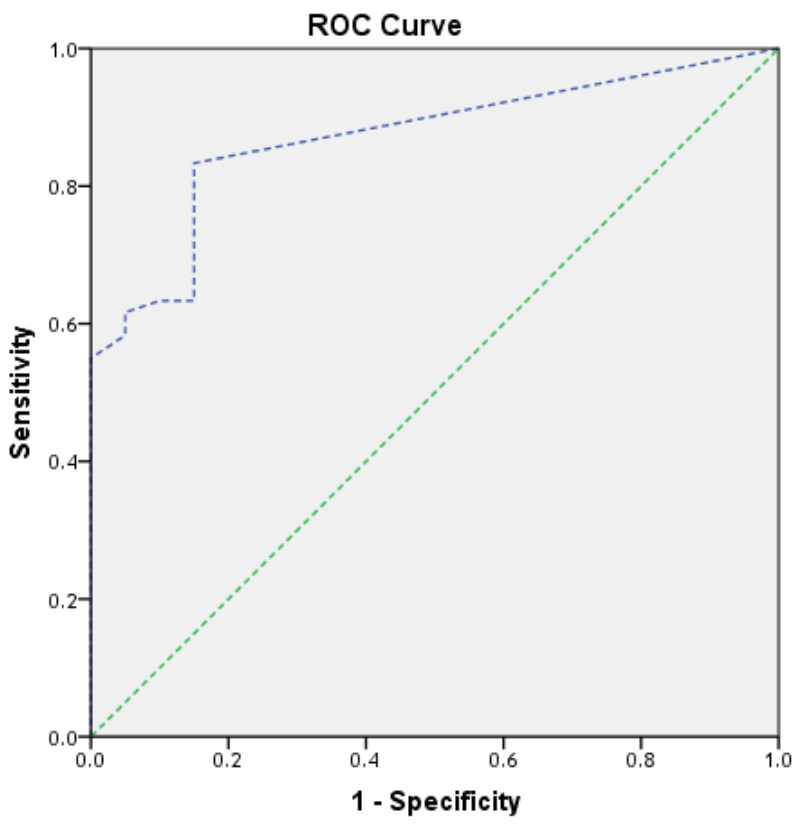

Diagonal segments are produced by ties.

VIR time cut off value $44 \mathrm{msec}$ has $83.3 \%$ sensitivity, $75 \%$ specificity, with $90.9 \%$ +ve predictive, $60 \%$-ve predictive and accuracy $81.2 \%$.

\section{DISCUSSION}

Tissue Doppler imaging (TDI) is a new echocardiographic technique well suited for the evaluation of longitudinal myocardial function, which is suspected to be initially affected in various cardiac diseases. Clinical studies have shown that TDI provides diagnostic and prognostic information incremental to conventional echocardiography in some cardiac diseases, although the primary TDI measure remains to be established. Conventional echocardiography is a strong predictor of death even in the general population, but whether preclinical left ventricular dysfunction by TDI has prognostic significance is unknown ${ }^{(\mathbf{1 8})}$.

In this study, we examined whether CAD in patients with apparently normal LV contraction is detected by a spectral TDI velocity mapping technique without any provocation. The presence of positive VIR as detected by spectral TDI mapping in 2- and 4-chamber views predicted CAD. This mapping technique had higher sensitivity than the standard spectral TDI measurements limited to the mitral annular levels. Postsystolic or postejection thickening, postsystolic motion, and PSS indicate a similar phenomenon by different methodologies ${ }^{(3,10)}$. A positive VIR detected by spectral TDI is a reflection of the delayed ejection motion of the myocardium during the isovolumic relaxation time. It has been shown to indicate severely ischemic myocar-dium ${ }^{(11,8)}$ Earlier studies suggested positive VIR was frequently observed in CAD. Voigt et al. ${ }^{(7)}$ demonstrated the increased amplitude of PSS during dobutamine stress echocardiography detected CAD using tissue Doppler strain rate imaging. Kondo et al. ${ }^{(\mathbf{1 2})}$ showed the delayed outward LV wall motion in the isovolumic relaxation phase was indicative of CAD using digital subtraction high-frame-rate echocardio-graphy. Similarly, using spectral TDI, the prolongation of isovolumic relaxation time could be suggestive of $\mathrm{CAD}^{(\mathbf{1 3 )}}$. These earlier studies were retrospective, and included patients with LV asynergy, which was readily detected by standard 2-dimensional echocardiography. Thus, whether the presence of positive VIR has diagnostic value in detecting CAD in patients with normally contracting LV remained unclear. Our study demonstrated the diagnostic value of 
positive VIR as an indicator of CAD in patients showing apparently normal LV contraction. LV diastolic function is frequently impaired before systolic function in patients with CAD. Kondo et al. ${ }^{(12)}$ reported abnormal relaxation is evident even in patients with CAD not associating systolic wall motion abnormalities. On the other hand, positive VIR may also occur in non ischemic conditions such as LV hypertrophy ${ }^{(\mathbf{1 4})}$ and $\mathrm{LBBB},{ }^{(\mathbf{1 5})}$ and even in healthy individuals ${ }^{(16)}$. Therefore, the diagnostic value of positive VIR in detecting CAD remained uncertain.

Localization of positive VIR should have reflected the location of the coronary artery stenosis. This discrepancy may be in part a result of the inadequacy in the number of mapping locations and tethering effects inherent to TDI velocity measure-ements.

Sophisticated color-coded TDI processing may help detect the location by demonstrating the localization compatible to the coronary arterial tree.

In this study, the duration of positive VIR was significantly longer in patients with CAD than in those without CAD. Interestingly, the positive VIR was not different between them. Possible explanations may include that myocardial velocity derived by TDI is affected by tethering effects and the Doppler angle of incidence. Normal myocardial velocities vary within the LV depending on the locations: the highest mostly at the base and the lowest around the apex from apical window, this in agreement with Toshinari Onishi, Masaaki Uematsu et al; $\mathbf{2 0 0 7}^{(\mathbf{1 7 )}}$ Thus, the timing analysis may provide more accurate information of patho-physiology than the magnitude of velocity in terms of TDI measurements.

Thor Evaderson et al., 2002 ${ }^{(\mathbf{8})}$ agrees with our study regarding PSS which is more commom in patient with significant $\mathrm{CAD}$ than non CAD patient.

Hoffman et al., 2011 ${ }^{(19)}$ studied eighty-four patients with angina pectoris, no previous history of ischaemic heart disease and normal left ventricular ejection fraction were examined with colour TDI, single-photon emission computed tomography (SPECT), and coronary angiography and agrees with our study in decrease Em in most studied segments in patient with significant CAD and decrease $S^{\prime}$ in the same patients.

Lee et al.,2005 ${ }^{(20)}$ studied 75 stable CAD patients .Conventional 2-dimensional-Doppler echocardiography and TDI were performed. Peak systolic (Sm), peak early (Em), and late (Am) diastolic mitral annular velocities measured at 4 sites (septal, lateral, inferior, and anterior) were averaged as global systolic and diastolic left ventricular function, respectively. The results was: CAD patients had significantly lower S', Em, $\mathrm{Em} / \mathrm{Am}$ ratio, and a higher ratio of early transmitral flow E-velocity over Em (E/Em) when compared with controls (all $\mathrm{P}<.05$ ).

This disagree regarding decrease of $\mathrm{S}^{\prime}$ which has significant difference between the studied groups at mid anterior, mid lateral and mid septal walls only and also decrease of Em wave which has significant difference between the studied groups at mid anterior, mid lateral, basal inferior and basal septal walls only.

\section{REFERENCES}

1. Murray CJ, Lopez AD. Mortality by cause for eight regions of the world: global burden of disease study. Lancet 1997;349: 1269-76.

2. Bonow RO, Smaha LA, Smith SC Jr, Mensah GA, Lenfant C. World heart day 2002: the international burden of cardiovascular disease; responding to the emerging global epidemic. Circulation 2002;106:1602-5.

3. Kukulski T, Jamal F, Herbots L, D'hooge J, Bijnens $\mathrm{B}$, Hatle $\mathrm{L}$, et al. Identification of acutely ischemic myocardium using ultrasonic strain measurements: a clinical study in patients undergoing coronary angioplasty. J AmColl Cardiol 2003;41: 810-9.

4. Song JK, Song JM, Kang DH, Haluska B, Marwick TH. Postsystolic thickening detected by Doppler myocardial imaging: a marker of viability or ischemia in patients with myocardial infarction. Clin Cardiol 2004;27:29-32.

5. Skulstad H, Edvardsen T, Urheim S, Rabben SI, Stugaard M, Lyseggen E, et al. Postsystolic shortening in ischemic myocardium: active contraction or passive recoil? Circulation 2002; 106:718-24.

6. Garcia MJ, Rodriguez L, Ares M, Griffin BP, Klein $\mathrm{AL}$, Stewart WJ, et al. Myocardial wall velocity assessment by pulsed Doppler tissue imaging: characteristic findings in normal subjects. Am Heart J 1996;132:648-56.

7. Voigt JU, Exner B, Schmiedehausen K, Huchzermeyer C, Reulbach U, Nixdorff U, et al. Strain-rate imaging during dobutamine stress echocardiography provides objective evidence of inducible ischemia. Circulation 2003;107: 2120-6.

8. Edvardsen T, Urheim S, Skulstad H, Steine K, Ihlen $\mathrm{H}$, Smiseth OA. Quantification of left ventricular systolic function by tissue Doppler echocardiography: added value of measuring preand postejection velocities in ischemic myocardium. Circulation 2002;105:2071-7.

9. Sahn DJ, DeMaria A, Kisslo J, Weyman AE, the Committee on M-Mode Standardization of the American Society of Echocardiography. Recommendations regarding quantitation of M-mode echocardiography: results of survey of echocardiographic measure-ments. Circulation 1978;58:1072-83. 
10.Skulstad H, Edvardsen T, Urheim S, Rabben SI, Stugaard M, Lyseggen E, et al. Postsystolic shortening in ischemic myocardium: active contraction or passive recoil? Circulation 2002; 106:718-24.

11. Derumeaux G, Ovize M, Loufoua J, Andre-Fouet $\mathrm{X}$, Minaire $\mathrm{Y}$, Cribier A, et al. Doppler tissue imaging quantitates regional wall motion during myocardial ischemia and reperfusion. Circulation 1998;97:1970-7.

12. Kondo $\mathrm{H}$, Masuyama $\mathrm{T}$, Ishihara $\mathrm{K}$, Mano $\mathrm{T}$, Yamamoto K, Naito J, et al. Digital subtraction high-frame-rate echocardiography in detecting delayed onset of regional left ventricular relaxation in ischemic heart disease. Circulation 1995;91:30412.

13. Garcia-Fernandez MA, Azevedo J, Moreno M, Bermejo J, Perez-Castellano N, Puerta P, et al. Regional diastolic function in ischaemic heart disease using pulsed wave Doppler tissue imaging. Eur Heart J 1999;20:496-505.

14. Pai RG, Gill KS. Amplitudes, durations, and timings of apically directed left ventricular myocardial velocities, II: systolic and diastolic asynchrony in patients with left ventricular hypertrophy. J Am Soc Echocardiogr 1998;11:1128.

15. Citro R, Galderisi M, Guarini P, Cicala S, Mattioli D, Bianco A, et al. Left bundle branch block with and without coronary artery disease: which value for a tissue Doppler-derived postsystolic motion? Ital Heart J 2003;4:706-12.

16. Voigt JU, Lindenmeier G, Exner B, Regenfus M, Werner D, Reulbach $U$, et al. Incidence and characteristics of segmental postsystolic longitudinal shortening in normal, acutely ischemic, and scarred myocardium. J Am Soc Echocardiogr 2003; 16:415-23.

17.Toshinari O, Masaaki U, Shinsuke N, Osamu L, takakazu M,JI kotani, et al. Positive Isovolumic Relaxation Velocity Detected by a Spectral Tissue Doppler Mapping Technique as an Indicator of Coronary Artery Disease: A Prospective Study( J Am Soc Echocardiogr 2007;20:158-164).

18. Wang M, Yip GW, Wang AY, et al. Peak early diastolic mitral annulus velocity by tissue Doppler imaging adds independent and incremental prognostic value. J Am Coll Cardiol 2003; 41: 820826

19. Hoffmann S, MogelvangR,Olsen NT,et al., Tissue Doppler echocardiography reveals distinct patterns of impaired myocardial velocities in different degrees of coronary artery disease Eur J Echocardiogr 2011 (6): 544-549.

20.Lee KW, Blann AD, Lip GY. Impaired tissue Doppler diastolic function in patients with coronary artery disease: relationship to endothelial damage/ dysfunction and platelet activation Am Heart J. 2005 Oct ;150(4):756-66 